\title{
How Accurate Appraisal of Behavioral Costs and Benefits Guides Adaptive Pain Coping
}

\begin{abstract}
Wiebke Gandhi ${ }^{1,2,3 *}$, India Morrison ${ }^{4}$ and Petra Schweinhardt ${ }^{1,2,5,6}$
${ }^{1}$ Faculty of Dentistry, McGill University, Montreal, QC, Canada, ${ }^{2}$ The Alan Edwards Center for Research on Pain, McGill University, Montreal, QC, Canada, ${ }^{3}$ School of Psychology and Clinical Language Sciences, Centre for Integrative Neuroscience and Neurodynamics, University of Reading, Reading, United Kingdom, ${ }^{4}$ Center for Affective and Social Neuroscience, Department of Clinical and Experimental Medicine, Linköping University, Linköping, Sweden, ${ }^{5}$ Faculty of Medicine, Department of Neurology and Neurosurgery, McGill University, Montreal, QC, Canada, ${ }^{6}$ Interdisciplinary Spinal Research Group, Balgrist University Hospital, Zurich, Switzerland
\end{abstract}

OPEN ACCESS

Edited by:

Juan J. Canales,

University of Leicester,

United Kingdom

Reviewed by:

James W. Grau,

Texas A\&M University,

United States

Ihssane Zouikr,

RIKEN Brain Science Institute

(BSI), Japan

Rabih A. Moshourab,

Charité Universitätsmedizin

Berlin, Germany

*Correspondence:

Wiebke Gandhi

w.gandhi@reading.ac.uk

Specialty section: This article was submitted to

Neuropharmacology,

a section of the journal

Frontiers in Psychiatry

Received: 11 May 2016

Accepted: 26 May 2017

Published: 12 June 2017

Citation:

Gandhi W, Morrison I and Schweinhardt P (2017) How

Accurate Appraisal of Behavioral Costs and Benefits Guides Adaptive

Pain Coping.

Front. Psychiatry 8:103.

doi: 10.3389/fpsyt.2017.00103
Coping with pain is a complex phenomenon encompassing a variety of behavioral responses and a large network of underlying neural circuits. Whether pain coping is adaptive or maladaptive depends on the type of pain (e.g., escapable or inescapable), personal factors (e.g., individual experiences with coping strategies in the past), and situational circumstances. Keeping these factors in mind, costs and benefits of different strategies have to be appraised and will guide behavioral decisions in the face of pain. In this review we present pain coping as an unconscious decision-making process during which accurately evaluated costs and benefits lead to adaptive pain coping behavior. We emphasize the importance of passive coping as an adaptive strategy when dealing with ongoing pain and thus go beyond the common view of passivity as a default state of helplessness. In combination with passive pain coping, we highlight the role of the reward system in reestablishing affective homeostasis and discuss existing evidence on a behavioral and neural level. We further present neural circuits involved in the decision-making process of pain coping when circumstances are ambiguous and, therefore, costs and benefits are difficult to anticipate. Finally, we address the wider implications of this topic by discussing its relevance for chronic pain patients.

Keywords: behavioral control, active compensatory coping, adaptive pain coping, maladaptive pain coping, mesolimbic dopamine system

\section{INTRODUCTION}

Pain is per definition an unpleasant sensation and signals (potential) harm to the organism (1). It therefore requires attention and needs to be addressed by the individual. Evidence suggests that pain triggers behavioral coping responses-aiming to reduce unpleasantness and harm, and to reach the best hedonic state possible within the given situation. In this article we discuss a variety of behaviors that are frequently exhibited to cope with a painful event. We further attempt to disentangle how characteristics of the painful stimulus itself as well as situational and personal factors influence the appraisal of costs and benefits, which ultimately determines the choice of a particular coping strategy via a complex network of relevant neural circuits. 
Coping with pain arguably serves two objectives: to (i) eliminate or reduce pain and (ii) continue to pursue valued activities despite pain (2). During active coping, the organism focusses on external stimuli and addresses them directly (3). Major active coping strategies encompass behaviors such as escaping, avoiding, or attacking the source of pain (4), but possibly also actions aimed to offset the unpleasant component of pain via active pursuit of pleasurable stimuli or events in the environment. During passive coping, the organism shows decreased responsiveness to external stimuli and focusses on affect regulation (3). Major passive coping strategies are quiescence, pain acceptance, and forms of surrender (including relegating the locus of control to external forces). Active and passive coping strategies may prove beneficial or disadvantageous depending not only on characteristics of the pain itself (i.e., whether it is objectively escapable or not) but also on personal factors (individual learning history with similar situations) and situational aspects, such as opportunities provided by the environment to allow for certain strategies (Figure 1). The organism has to (unconsciously) appraise the behavioral costs and the anticipated benefits for the different available strategies to (unconsciously) choose the most economical one. An accurate appraisal of the cost/benefit ratio will guide adaptive pain coping behavior. For pain that is escapable, active coping strategies are likely to be adaptive, because the behavioral costs are comparatively little given the benefit of ceasing the pain. However, if the organism has experienced little or no success with a certain active coping strategy in the past (for example, attacking the source of pain), and the situation does not allow for an alternative active strategy (e.g., flight), the most adaptive strategy is likely passive surrender (i.e., lower the costs) and pain endurance-the energy expenditure is minimized and the body gains time to heal (i.e., greatest anticipated benefit).

Similarly, if pain stems from an objectively inescapable source (e.g., visceral pain, inflammation), passive coping in the form of quiescence is likely to be adaptive. By reducing movement and allowing healing, quiescence might even help to avoid further damage. Beyond the concept of passivity as a default state of individuals who have not learned to control a certain stressor [put forward by Maier and Seligman (5)], we portray passive coping as an adaptive strategy when dealing with ongoing pain. Passive coping, including pain acceptance, encompasses engagement with the pain symptoms (6) and requires an active learning process. "Learned controllability" (5), for instance, can hinder pain acceptance-an individual who has learned to be generally in control of physical stressors may find it difficult to accept and endure pain. In contrast, once pain acceptance has been successfully acquired as a coping strategy, cognitive resources become available to focus on the surroundings. If incentives are present, it would be most adaptive to focus on their pursuit to offset the unpleasant sensation caused by ongoing, inescapable pain.

In this review, we present pain coping as an unconscious decision-making process during which accurately evaluated costs and benefits of behavioral choices lead to adaptive pain coping behavior. We also review the neurobiology underlying this behavior. Neural circuits involved in pain coping can trigger the dopaminergic system and thereby support vigilance toward

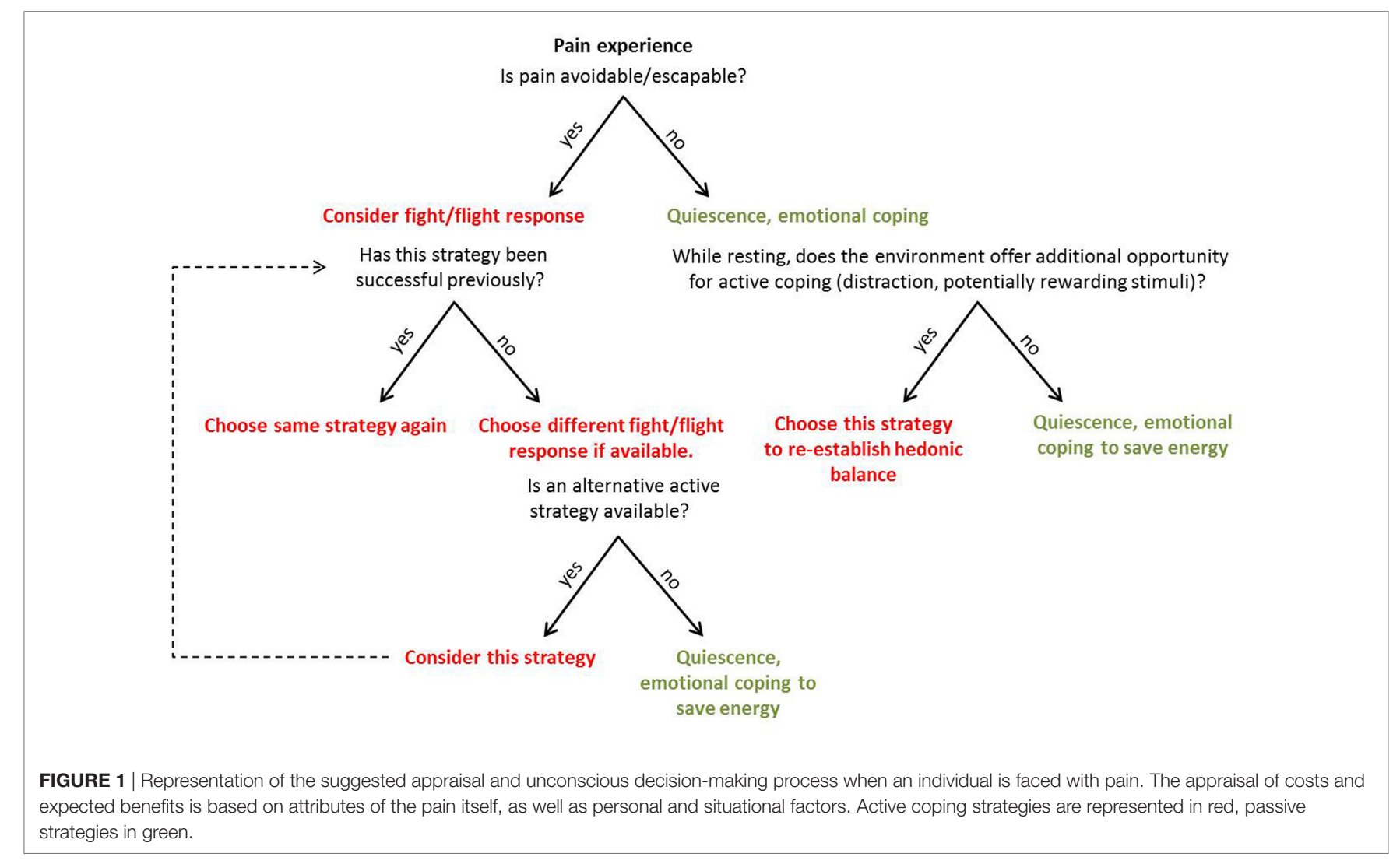


rewarding stimuli while in pain. We argue that these mechanisms are of central importance to coping with ongoing, unavoidable pain. In the final part of the article we focus on alterations of the brain's dopamine system as one of the neurobiological obstacles hindering adaptive coping in pain patients.

\section{BEHAVIORAL FINDINGS FOR ACTIVE AND PASSIVE PAIN COPING}

\section{Active Escape from Acute Pain: From Reflexes to Complex Behaviors}

Pain warns the organism of (potential) harm and calls for a quick coping action, e.g., the withdrawal of the affected body part from a harmful source or the escape from an unsafe environment. Ultimately, the organism will likely learn from the unpleasant experience and, in the future, adapt their behavioral response to the threat (e.g., an environment, a certain action, or a specific stimulus), which led to pain. Accordingly, Morrison and colleagues portrayed pain as an "action problem" (7) highlighting the necessity of immediate nocifensive behavior when facing potential injury. One of the simplest forms of nocifensive behavior is the withdrawal reflex. While reflexes provide a rapid initial action to prevent harm and to eliminate pain, more complex mechanisms allow for refined nocifensive behaviors (8). For example, early experiments in canines demonstrated that naive dogs receiving escape-avoidance training show fear-like behavior in response to nociceptive electrical stimulation until the dog finally escapes to safety [e.g., jumping over a barrier to the safe compartment of a shuttle box (9)]. With every new exposure to the same aversive stimulation, the dogs showed the escape response faster and, thus, learned "mastery" (5). Similarly, human participants show faster reaction times during acute pain (10), suggesting a facilitation of the motor actions that would enable quick voluntary escape or avoidance responses. The neural underpinnings of this phenomenon are discussed in the Section "Neurobiological Correlates of Active and Passive Coping."

\section{Passive Endurance of Escapable Pain: Adaptive and Maladaptive Behaviors}

In certain situations, it is adaptive to endure pain even when it could be escaped and thus eliminated. For example, we might accept the pain of dental treatment because of the anticipated future benefit (e.g., increased dental hygiene, prevention of dental damage). The decision-making based on the comparison between costs and benefits/reward in the pain context has been formalized in the "Motivation-Decision Model" $(11,12)$. In this model, pain and reward are understood as interacting aversive and appetitive motivational systems. The individual (e.g., the patient at the dentist's) has to prioritize one or the other, based on personal factors (How much do I value dental hygiene?), learning history (I survived the last treatment), and situational factors (Does the environment offer a way to escape the pain and still get the benefits, maybe in form of local anesthesia?).

While adaptive in certain situations, passive endurance of escapable pain can be maladaptive under different circumstances. About 50 years ago, the phenomenon of "learned helplessness" was first described (13). It refers to passive pain coping of animals in a situation where pain can be escaped and would be objectively more adaptive than passivity. However, the animals had been exposed to unavoidable nociceptive foot shocks in a different environment several hours before [e.g., Ref. (13-18)]. During this initial procedure of receiving inescapable shocks, the animals learn that shock termination is independent of their behavioral responses. Receiving shocks in a new environment, the expectation of not being in control is generalized, and the organism fails to learn appropriate escape behavior [reviewed in Maier and Watkins (19)]. The phenomenon of learned helplessness has been replicated experimentally in humans after exposure to inescapable noise [e.g., Ref. $(20,21)]$. It was conceptualized that the person's attributional style would determine whether the individual was likely to develop generalized helplessness after experiencing uncontrollability over a stressor $(21,22)$. According to this attributional theory of learned helplessness, people who attribute a lack of control over negative events to permanent causes (e.g., stress is always uncontrollable) and pervasive factors (e.g., most of my problems are unsolvable) are more vulnerable to generalize helplessness $(5,21-23)$.

Although it has not been directly tested, we posit that the phenomenon of learned helplessness is of crucial importance to the pain field. The treatment of pain often includes pharmacological approaches, but many patients still continue to experience substantial levels of pain (24) and often describe the treatment effects as unreliable and dissatisfactory (25). This leaves the patient with little or no control over their condition. As described above, learning that their own behavior has no consequence on the stressor (i.e., the pain) leads to learned helplessness in vulnerable individuals. Learned helplessness in humans has been associated with motivational and cognitive deficits, and emotional disturbances (22), which are indeed commonly described by pain patients (26-29).

The examples above highlight how similar behaviors in response to pain can be adaptive or maladaptive, depending on the accuracy of the individual's appraisal of the relevant factors. Pain coping can, in fact, be described as a decision-making process based on the appraisal of costs and expected benefits (11, 12). In the example of the patient undergoing a dental procedure, costs and benefits are realistically anticipated, leading to the conclusion that benefits are greater than costs and therefore, tolerating pain is adaptive. In the instance of helplessness, however, costs are considered unrealistically high while-falsely-no or little benefit is being anticipated. This false appraisal of the cost/ benefit ratio leads to unnecessary pain suffering, the perception of uncontrollability, and long-term emotional disturbances (22) and is thus considered maladaptive.

\section{Passive/Emotional Coping When Pain Is Unavoidable: Positive Pain Management, instead of Perseverance in Unsuccessful Attempts to Eliminate Pain}

Even in many acute pain situations, escape or avoidance of the pain-provoking stimulus is not possible: an inflamed wound, toothache, or visceral pain are examples of acute pain situations 
that we are unable to escape from. Under these circumstances, it is often advantageous to engage in a passive/emotional coping style: the affected body part or the whole body is immobilized, and blood pressure and heart rate decrease $(4,30,31)$, helping the body to rest and heal. One central concept within emotional coping strategies is pain acceptance. Though pain acceptance has sometimes been equated with "giving up," it actually constitutes an active engagement with the pain. In contrast to helplessness, pain acceptance is based on an accurate appraisal of costs and benefits, with the realistic conclusion that the costs to fight (unavoidable) pain are too high given the low probability of benefits. It describes a readiness to accept the presence of pain and its inescapability, while no energy is being wasted to persevere in the attempt to change what cannot be changed $(6,24)$. Pain acceptance increases cognitive capacities and allows attending to rewarding events and stimuli in the environment while pain is ongoing. In the following paragraph, we discuss in more detail how reaching out for positive means describes an adaptive active coping style when dealing with unavoidable/inescapable pain.

\section{Reaching Out for Positive Means: Active Compensatory Coping When Pain Is Unavoidable}

When inescapable/unavoidable pain is well managed via passive/emotional coping, cognitive capacities become available to focus on life-relevant and rewarding events. We classify the approach to screen the environment for incentives as an active pain coping attempt with the aim to reestablish the hedonic homeostasis, which is disturbed by the unpleasant experience of pain (1). Consistent with this, healthy individuals show increased motivation to obtain reward when in pain (32), presumably to compensate for the negative emotional state caused by pain and to reestablish the hedonic homeostasis. In our study, participants showed increased efforts (faster reaction times) to obtain high monetary reward when in pain compared to when they were pain-free. We concluded that vigilance for environmental cues with the potential to improve the hedonic state was increased by the ongoing pain stimulus. Comparable results have been found in rodents (33): acutely injured rats spent more time in near proximity to rewarding food pellets in the middle of an open field arena than control animals (33).

The fact that humans perform better when in pain is remarkable, given that pain demands attention and has been described as reducing the availability of cognitive resources (34-36). To resolve this apparent contradiction, it is important to consider whether the outcome of the task is of relevance to the participant's state. In general, individuals are more sensitive to information that is pertinent to reach a certain goal; goal-irrelevant information, in contrast, is likely to be ignored [reviewed in Van Damme et al. (37)]. In analogy, while in pain, the sensitivity toward incentives associated with rewarding outcomes-as well as toward negative cues threatening to further worsen the homoeostatic imbalance-would be increased, because it assists in achieving the goal to reestablish hedonic homeostasis. Conversely, during goalirrelevant tasks that do not impact the homeostatic balance while in pain, such as mental arithmetic, memory, or discrimination tasks, the performance is worse compared to a pain-free state, as shown in many experimental studies [e.g., Ref. (35, 38-40)]. Interestingly, experimental studies have shown that chronic pain patients (41-43) and healthy participants in acute pain (44) choose options associated with high immediate reward, while ignoring the fact that this choice is associated with higher risk and thus less advantageous in the long term. This fits the notion that ongoing or persistent pain makes individuals more sensitive to immediate rewards and less sensitive to long-term disadvantageous consequences. This phenomenon does not seem to be restricted to humans: rats with persistent inflammatory pain were shown to choose a lever associated with higher, but less frequent rewards over a safer option associated with smaller immediate rewards (45). We propose that individuals with ongoing pain focus on environmental cues that offer an opportunity to immediately improve their hedonic imbalance, i.e., high incentives, while higher-order processing of odds and potential risks is diminished. Furthermore, the experience of winning is itself analgesic $(46,47)$. Thus, reaching out for positive means-i.e., showing an increased effort to obtain reward-constitutes an active coping style with a twofold benefit when pain itself cannot be avoided or escaped: obtaining reward reestablishes or at least improves the hedonic homeostatic balance and reduces the perception of the pain. It is conceivable that such active compensatory coping might even occur when the rest of the body is in passive coping mode. That is, the affected body site or the whole body is kept at rest while the mind stays alert, screening the environment for incentives signaling the potential of immediate reward.

\section{NEUROBIOLOGICAL CORRELATES OF ACTIVE AND PASSIVE COPING}

Studies on the neurobiology underlying pain coping have often used escapable and inescapable stimuli to investigate coping responses in animals. As expected, the former are typically associated with active escape responses, while the latter are related to passive strategies (4). However, as discussed above, organisms may react with passivity to stimuli that are objectively avoidable; and vice versa may use active coping strategies while healing from unavoidable pain is taking place (e.g., reaching out for positive means). In the following paragraphs, we discuss the neural substrates underlying the complex interacting influences of pain and individual circumstances on coping behavior.

\section{Coping in Response to Objectively Escapable Pain}

Rodent studies demonstrate that generally, escapable acute pain, such as short-lasting superficial noxious stimulation of the skin and mainly mediated by A-delta fibers (e.g., pinches, pricking, and noxious heat stimulation), elicits active coping behaviors, accompanied by excitation of the sympathetic nervous system $(31,48,49)$. One of the simplest forms of nocifensive behavior is the withdrawal reflex (7). At the dorsal horn of the spinal cord, the afferent nociceptive signal is conveyed directly or indirectly to spinal motor neurons to facilitate the withdrawal reflex. While reflexes provide a rapid initial action to prevent harm and to 
eliminate pain, more complex midbrain and cortex-regulated mechanisms allow for refined nocifensive behaviors. The dorsolateral periaqueductal gray (dlPAG) receiving mainly input from superficial A-delta fibers is key in orchestrating active coping responses $(4,30,50)$. An important cortical site for integrating visual, auditory, and somatosensory information with movement toward or away from the harmful source is suggested to be the superior parietal cortex, as identified in a human fMRI experiment (51). To our knowledge, no evidence exists for direct connections between the dlPAG and the superior parietal cortex, but a human diffusion MRI study showed connectivity between these two regions (52). Therefore, dlPAG-parietal cortex connections might be the neural substrate of active nocifensive behavior in response to escapable pain in humans.

Active pain coping triggered by A-delta input into the dlPAG is modulated by top-down mechanisms. The rodent literature shows that the medial prefrontal cortex (mPFC) evaluates the escapability of pain [reviewed in Maier and Seligman (5)]. If a stimulus is deemed escapable, the mPFC allows the dlPAG to exhibit an active coping response. Indirect projections have been shown to be important for active pain coping: inhibition of the dorsal raphe nucleus (DRN) by the mPFC disinhibits the dlPAG [reviewed in Maier and Seligman (5); Figure 2], thereby allowing fight or flight responses $(4,30,50)$. In addition, direct anatomical connections between the mPFC and the dlPAG might also be involved in mediating active pain coping responses: the $\mathrm{MPFC}$ has been shown in rodents and macaque monkeys to project directly to the dlPAG $(53,54)$. In fact, such projections have recently been identified in mice as playing an important role for social defensive responses (55). In humans, the $\mathrm{mPFC}$ has been described to form and store schemata that integrate context, events, and appropriate action [reviewed in Euston et al. (56)]. The purpose of these schemata is to initiate the most suitable emotional and motor response to a given event, based on past experiences. Based on these lines of evidence, we speculate that also in humans, the dlPAG is disinhibited via the mPFC if the appraisal of pain results in the interpretation that it can be escaped, and consequently prepares the body for active coping.

In situations where the painful stimulus is not identified as escapable, the dlPAG and its functions are inhibited via neural networks identified in non-human studies (5). When pain is deemed inescapable, the mPFC does not inhibit the DRN, which is activated via excitatory nociceptive input from the habenula and locus coeruleus (57-59). Activity in the DRN suppresses activity in the dlPAG via serotonergic projections (60) and

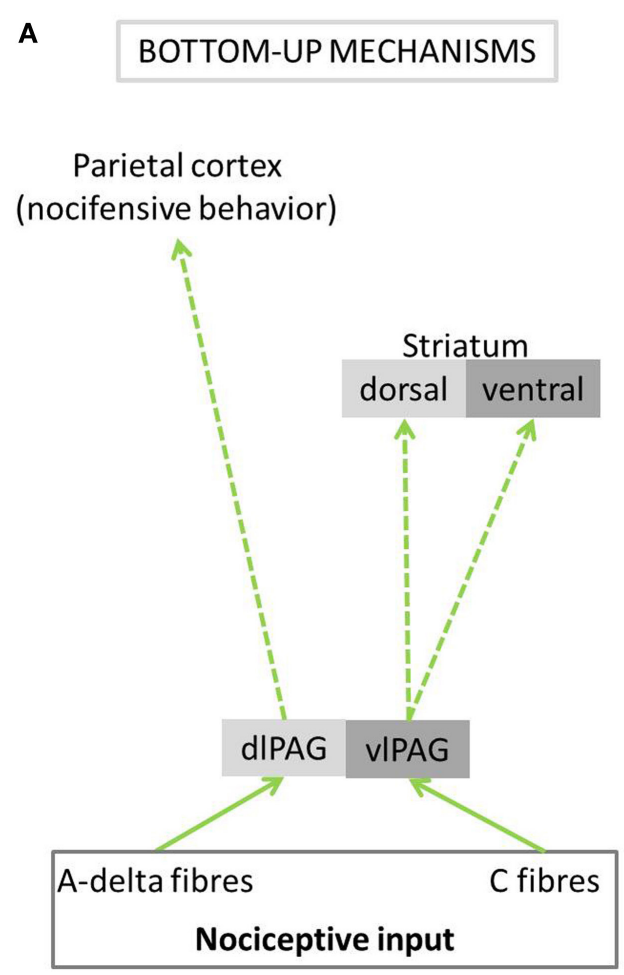

B

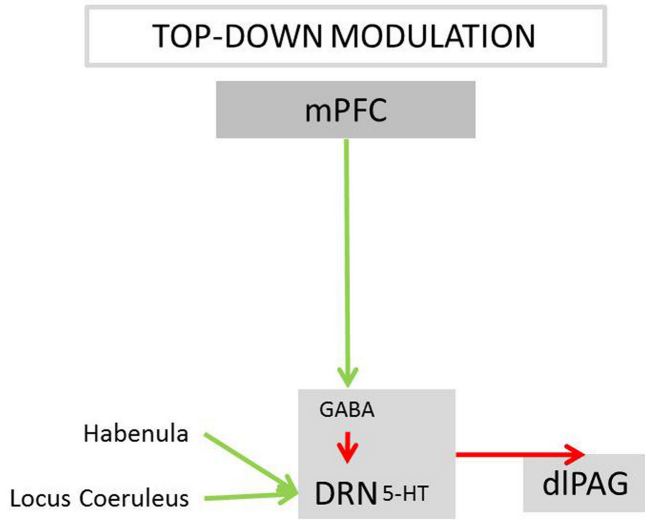

FIGURE 2 | Bottom-up pathways of active and passive pain coping and its modulation by top-down mechanisms. The PAG is a central brain structure in pain coping, preparing the body for either fight/flight responses or passive endurance of the painful stimulus. (A) Different parts of the PAG receive nociceptive input from A-delta or C-fibers. (B) The PAG is modulated, via the DRN, by the MPFC, which signals subjectively perceived control over a painful event. PAG, periaqueductal gray; dIPAG, dorsolateral periaqueductal gray; vIPAG, ventrolateral periaqueductal gray; DRN, dorsal raphe nucleus; 5-HT, serotonin; GABA, gamma-aminobutyric acid; mPFC, medial prefrontal cortex; green arrows, excitatory activation; red arrows, inhibition; dashed arrows, anatomical connections postulated to underlie coping behavior in response to pain; solid arrows, anatomical connections shown to play a role in nociceptive processing or the modulation of behavior when expecting or experiencing pain. 
thereby triggers behavioral passivity. The serotonergic pathways from the DRN further activate the amygdala (61), which results in the emotional experience of fear.

The periaqueductal gray (PAG) also seems to code negative prediction errors, which has been described in humans using functional magnetic resonance imaging (62). Negative prediction errors in these circumstances describe the experience of a painful stimulus that was (falsely) evaluated as avoidable, i.e., the outcome was worse (more painful) than expected. This information is being fed back to the mPFC to update expectations for future pain events (62). This suggests that a similar pain event in the future will less likely be considered escapable; this, in turn will result in decreased dlPAG activation ( $v i a$ the top-down pathways described above) and therefore lead to decreased active escape behavior or even behavioral passivity.

\section{Coping in Response to Objectively Inescapable Pain}

Objectively unavoidable acute pain, such as deep somatic or visceral pain, is conveyed by $\mathrm{C}$-fiber input into the ventrolateral periaqueductal gray (vlPAG), which triggers passive coping behaviors and downregulation of the sympathetic nervous system in rodents $(4,30)$. Keay et al. (63), for instance, demonstrated that tonic nociceptive stimulation of the neck (deep muscle stimulation by $5 \%$ formalin solution or cutaneous stimulation by a neck clip) increased quiescence compared to control rats, which was associated with a selective increase of a marker of neural activity, c-Fos, in the vlPAG. As explained in the section above, serotonergic neurons of the DRN are activated simultaneously via the locus coeruleus and the habenula of the descending antinociceptive system (57-59). By activation of the raphe nucleus, serotonin is being released from axons in the spinal cord, which produces an analgesic effect by inhibiting incoming nociceptive signals [e.g., Ref. (64)]; the pain can thus be endured more easily. These mechanisms support passivity and quiescence of the body to allow healing and regaining of energy.

Of interest for this article are not only the afferent but also the efferent connections of the PAG, particularly to the dopaminergic structures ventral tegmental area (VTA) and substantia nigra identified by tracer studies in rodents (65-67). The PAG input to the nigrostriatal dopaminergic system via the substantia nigra pars compacta originates mainly in the ventral aspect of the PAG (65). Considering the central role of the nigrostriatal system in initiating and preparing motor responses demonstrated by lesion studies [e.g., Ref. $(68,69)$ ], this system is a candidate substrate for increased motor performance in response to reward-associated stimuli while experiencing inescapable pain (see Reaching Out for Positive Means: Active Compensatory Coping When Pain Is Unavoidable). In contrast to the substantia nigra, the PAG input into the VTA does not seem to be restricted to one specific aspect of the PAG but originates from ventrolateral as well as dorsolateral columns (67). Within the VTA, these PAG efferents target dopaminergic neurons in the paranigral and the parabrachial subregions (67), providing a circuitry via which nociceptive input could trigger the mesolimbic dopaminergic system. In line with the anatomical circuitry, dopamine is released in the basal ganglia, including the striatum, in response to experimental pain in rats $(70)$ and humans $(71,72)$. Dopamine release in response to acute pain has been described to serve the primary purpose to initiate pain-relevant behaviors helping the organism to either endure or avoid the pain depending on the situational circumstances [reviewed in Taylor et al. (73)]. Outside pain, dopamine plays a key role for reward processing (74-79): dopamine release is associated with enhanced awareness of stimuli signaling potential reward leading to increased motivation to obtain reward in animals and humans $(74,76,80,81)$. Thus, ventral striatal dopamine release in response to pain-presumably triggered by the PAG via the VTA-is well positioned to enhance the salience of incentives in the environment and thereby underlie the increased motivation to obtain reward observed in acute unavoidable pain. Considering that dorsolateral as well as ventrolateral columns of the PAG connect to the VTA, this might happen not only during coping with objectively inescapable pain but also during coping with escapable pain. In fact, dopamine release in the mesolimbic dopamine system of rats predicts successful avoidance of foot shocks (82), which can be interpreted as a positive expectation that the hedonic homeostasis will not be disturbed-in this instance, successful pain avoidance would have a similar reinforcement value as obtaining appetitive stimuli. In either instance-active or passive coping-dopamine release in the mesolimbic system would be an adaptive mechanism by which the brain tries to reestablish or maintain the affective homeostatic balance.

\section{Coping under Ambiguous Circumstances: Prediction and Control in Striatal-Cortical Circuitry}

Above, we have relatively simplistically differentiated between escapable/avoidable and inescapable/unavoidable pain. In real life, pain stimuli lie on a spectrum of "avoidability." For example, a certain price has to be paid to avoid pain or with a certain behavior pain can be decreased but not completely avoided. For any situation in which pain does not lie on either end of the spectrum, action selection and prioritization has to take place while accepting uncertainty about the costs/benefit ratio. In this section, we will discuss the neurobiology of these phenomena.

When pain is neither unambiguously escapable nor unambiguously inescapable, neural circuits in the central nervous system operate both to predict potentially noxious circumstances and to control behavior accordingly. These processes rely heavily on experience and learning and involve (voluntary) action selection. Depending on whether pain is acute (injury is experienced or anticipated), or whether it occurs in a post-injury context (in a healing phase), pain-related signaling will prompt different behavior and enlist different ensembles of neural circuits. Aversive responses during acute pain usually occur in the context of injury or threat of injury, referred to here as "peri-injury" pain processing. Generally, a "go" decision-escape or avoidance-is optimal in peri-injury pain processing, because the benefit of pain elimination seems to outweigh the behavioral cost. In contrast, "post-injury" pain processing occurs after tissue has been damaged, and behavior that promotes healing is prioritized, including quiescence and inhibition of normal behavioral activity 
(any attempt to eliminate the pain, i.e., behavioral cost would be greater than the benefit). Generally, a "stay" decision-rest and recuperate-is therefore optimal in post-injury pain processing.

Neural mechanisms of prediction and control in peri-injury processing involve the striatal dopamine circuits discussed above, as well as cortical circuits with which they interact. This involves instrumental reinforcement learning about actions and outcomes. For example, when an action carries both costs and benefits, responses in ventral ACC and ventral striatum are attenuated when the predicted costs outweigh the benefits-this attenuation increases with an increase of the negative relation of costs over benefits (83). The greater the amount of additional information needed to select an appropriate action, the greater the demand for higher-order levels of control via cortical networks. In a hierarchical "cascade," various nested levels are subsumed, ranging from immediate context, memory, and any relevant contingencies or rule-based information (84). This results in more flexible and discretionary forms of control, going beyond reflex action or the more binary on-off control of inhibitory feedback loops. Subregions of the ACC probably work together to integrate stimulus content and current task demands to produce appropriate and timely responses $(85,86)$. These mechanisms are likely to be critical for active coping in the face of pain.

There is evidence that simpler levels of the control hierarchy in cingulate cortex are located more caudally (for example, in dorsal posterior cingulate cortex), and increasingly more nested and complex levels in the more rostral direction [for example, the rostral, perigenual portions of the dorsal ACC $(7,87)]$. Recent human neuroimaging evidence indicates that voluntary motor-related processing can account for MCC activation during pain, particularly in the caudal cingulate motor zone (CCZ) (10). Rostral ACC regions are particularly densely interconnected with dorsomedial and dorsolateral prefrontal networks that are also implicated in executive processing and action selection. These areas may contribute to a ranking of choices in both current and prospective temporal windows (88).

ACC and insular cortices are interconnected and highly coactive during pain, as well as in a range of other contexts (89). In situations involving acute pain, predictive dynamics between ACC and anterior insula (AI) probably reflect processing related to assigning priority to a stimulus and selecting an action in voluntary responses to pain (7). The organization of pain processing shows evidence of a caudorostral gradient in the insula, in terms of connectivity and roles in distinct cortical networks $(90,91)$, reaching a high degree of integration in AI (92). Importantly, this integration probably occurs in a predictive manner, with AI activity predicting whether a subject will classify a stimulus as painful even before the stimulus occurs (93).

These cortical networks may also contribute to coping strategies. For example, the vlPAG is functionally connected with rostral ACC even during rest, when the brain is not receiving nociceptive input nor engaged by a task (94). In addition to the striatal functions described above, signaling in the striatum when anticipating pain may signal the expected value of a painful stimulus to the PAG, which communicates this signal to a wider cortical circuit that includes control-related regions of dACC (62). This is consistent with the PAG instigating dopamine release in the striatum and "energizing" active responses to ongoing pain. Dopamine-dependent circuits crucially support predictions about reward (95) as well as playing a central role in the implementation of such learning in the instrumental control of action.

The interesting case with respect to coping is when an individual makes active, peri-injury-like decisions under chronic or post-injury circumstances. What determines the shift from a passive to active coping mode in chronic pain? Individual differences in PAG-striatum-cortical network dynamics may play a role. For acute, unavoidable painful stimulation, healthy individuals differ in their learning biases (96): some individuals displayed a "negative" learning pattern in which pain drives aversive learning, while others displayed a "positive" pattern in which learning is driven more by success in avoiding pain. These individual differences were associated with differential responses in the striatum and were predicted by striatal gray matter density (96). The complex striatocortical architecture of control and prediction neurocircuitry in pain behavior reflects the fact that broad behavioral strategies like "go" or "stay" can be generally effective under certain sets of circumstances but may not necessarily prove beneficial with respect to pain outcomes in any given situation, for example, as when subjective pain outcomes in chronic pain would improve by shifting to an active strategy.

\section{COPING AND CHRONIC PAIN}

Thus far, we have presented fundamental principles of pain coping and its underlying neurobiology. In the last section of this article, we discuss the relevance of these concepts and neural circuitries for chronic pain in more detail.

Per definition, chronic pain persists or recurs over a period longer than 3 months (97). This means that even for patients who have some control over their pain and can reduce or even avoid pain under certain circumstances, pain episodes are frequent and/or long enough to qualify as chronic pain. Nevertheless, it would be too simple to view chronic pain merely as being unavoidable. How avoidable chronic pain episodes are perceived as encompasses a wide spectrum. Some types of chronic pain lie at the extreme end and are practically unavoidable, such as nonevoked neuropathic pain. Other types, such as movement-related pain in osteoarthritis, might be largely avoidable, as long as the individual adjusts his or her behavior accordingly. These two examples illustrate the two major goals of coping with chronic pain: pain reduction on the one hand and on the other hand, the continued pursuit of valued activities and life goals (2), despite pain

As the example of movement-related pain, the goals of pain reduction and the continued pursuit of valued activities may be incompatible with each other and may be associated with conflicting motivations. Therefore, the need for valuation, goal setting, goal adjustment, and goal pursuit strategies becomes extremely important in the management of chronic pain. These are all processes necessitating active engagement of the patient. Indeed, active coping strategies in chronic pain patients with a focus on the pursuit of life-goals are associated with improved health and treatment outcomes $(98,99)$. Active coping in the context of chronic pain refers to accepting responsibility for 
dealing with one's pain and to be actively engaged in developing strategies for pain reduction and the pursuit of other life goals. The best care strategies for chronic pain require the patient to embrace lifestyle adaptations and self-management (100). Of course, active coping is not to be confounded with "activity no matter what." As discussed above, it is central to adaptive pain coping that costs and benefits are realistically appraised, while benefits should outweigh costs. In order to keep the costs within an appropriate range given the benefits, self-management encompasses activity pacing, in addition to behavioral persistence (101). Although emotional coping strategies are grouped under avoidant, and therefore passive, coping (102), we suggest that they are necessary to allow for active coping when unavoidable pain is present. Above, we introduced the concept of pain acceptance (i.e., a readiness to accept the presence of unavoidable pain, while not wasting energy on unsuccessful attempts to eliminate it) as an example of passive/emotional coping. This concept focuses on increased functionality despite having pain and enables the patient to focus on rewarding events in their environment. In fact, among chronic pain patients, the self-efficacious ones could be demonstrated to show less depressive symptoms and their pain interfered less with daily-life activities (103-106). We conclude that emotional coping is a central initial process, necessary to allow for adaptive active coping with chronic pain, for instance, by means of focusing on pleasurable events and increased functionality.

\section{Neurobiological Obstacles for Active Coping With Chronic Pain}

If a combination of pain acceptance and active (goal-pursuing) coping strategies are most adaptive for dealing with chronic pain, why do many patients persevere in their passivity, while avoiding the next important step of an active approach (101)? The answer encompasses different domains, ranging from psychological to neurobiological to societal phenomena. Psychological obstacles comprise, but are not limited to, avoidant behavior, including learned avoidance (a certain behavior is punished by experiencing pain), misinformed avoidance ("bending over is bad"), and affective avoidance (fear of pain) (107), learned helplessness (underestimating the benefit/cost ratio based on the individual learning history), and misguided reinforcement (e.g., pain behaviors are rewarded). Excellent reviews on psychological aspects of obstacles to coping with chronic pain have been published (107, 108); we attempt here to integrate this with neurobiological findings emerging in the chronic pain literature.

Several brain functions are required for active coping, such as an evaluation of the situation integrating past experiences (5), action selection (56), control of affect $(5,56)$, and goal adjustment. Not all these functions have been experimentally assessed in chronic pain patients; however, patients have been described to present with cognitive difficulties, including impaired decision-making (41-43). Further, it has become clear in recent years that dorsomedial and dorsolateral parts of the prefrontal cortex-each an integral component within striatal-cortical control networks-display structural and functional alterations in chronic pain patients [reviewed in Bushnell et al. (109) and
Smallwood et al. (110)]. Thus, cognitive functions important for active coping might be impaired in chronic pain patients due to brain alterations, which would be an important obstacle to adaptive coping. In addition, the $\mathrm{mPFC}$ is important for classifying a stimulus as being avoidable or controllable, as described above. A dysfunctional mPFC might be less capable of identifying when pain is controllable, leading via the DRN to an inhibition of the dlPAG. This in turn would impede active coping. Several lines of evidence indicate that structural brain changes are at least partly a consequence of pain or prolonged nociceptive input (111) and this could initiate a viscous circle or even a downward spiral of pain and unsuccessful coping.

A number of other neurobiological factors hinder successful active coping in chronic pain. As discussed above in Section "Neurobiological Correlates of Active and Passive Coping," active versus passive coping responses are influenced by bottom-up afferent input with C-fibers preferentially triggering passivity. Of course, chronic pain constitutes a heterogeneous group of different conditions, comprising among others neuropathic and inflammatory pains. Despite this heterogeneity, C-fibers, in particular from deep tissues and viscera, likely provide important afferent input in many chronic conditions. For example, central sensitization and wind-up, considered to be two important mechanisms operating in neuropathic pain, depend on C-fiber input into the spinal cord $(112,113)$. Under conditions of inflammation, "silent" nociceptors that, in healthy tissue, are mechanically insensitive and not activated even by strong stimuli, become excitable to pressure, changes in temperature, and tissue acidosis, which contributes to the generation and maintenance of hyperalgesia (114). In the joint, approximately one-third of sensory C-fibers and a small percentage of A-delta fibers are estimated to be mechano-insensitive silent nociceptors (114). Thus, the neurobiological coping response triggered by bottom-up input ought to be passivity in many chronic pain conditions, even when the pain is not accompanied by significant emotional distress. To perform active coping successfully, chronic pain patients thus have to overcome this neurobiology that defaults the individual to passivity. In addition to $\mathrm{C}$-fiber input promoting passivity, we and others have postulated that an "inactivity response" operates in some chronic pain patients that resembles the sickness response observed with systemic inflammation $(115,116)$. Such a response consisting of widespread pain, hypersensitivity to somatosensory as well as auditory or olfactory stimuli, stiffness, fatigue, lethargy, and depressed mood can be understood as an integrated program designed to force the organism to rest (116). This program would be beneficial and promote healing and recovery in situations of acute inflammation, infection, or certain types of visceral pain. However, activation of the inactivity responses by, e.g., psychological stressors or regional pain problems would be maladaptive, because quiescence neither leads to the elimination of the stressor in these situations nor does it improve the hedonic state or functionality. In many instances, passivity even aggravates the problem through deconditioning and withdrawal. Intriguingly, the symptom constellation of the inactivity response-widespread pain particularly in deeper tissues, hypersensitivity to somatosensory as well as auditory or olfactory stimuli, stiffness, fatigue, lethargy, and depressed mood-corresponds to 
the clinical picture of fibromyalgia and related "primary" pain conditions (97). The role nociceptive input from the periphery plays in primary pain conditions remains debated (97) and the potential neurobiology of the postulated inactivity response is currently unknown. Extrapolating from the classical sickness response, however, suggests that neuroinflammation might be a candidate mechanism (115). Activation of glia cells, an important constituent of neuroinflammation, has indeed been observed in the brains of patients with chronic low back pain (117).

Activated glia and an associated pro-inflammatory cytokine response in the CNS are known to have substantial effects on various neurotransmitter systems (118). Regarding the monoamine transmitters, which include serotonin, norepinephrine, and dopamine, cytokines impact on synthesis, re-uptake, and release, typically with the net effect of decreasing monoamine availability in the brain [reviewed in Miller et al. (118)]. Dopaminergic neurons in the substantia nigra have been shown to be particularly sensitive to inflammation (119), which is related to the high density of microglia in this region. This is interesting because it has become clear in recent years that chronic pain is associated with changes in the brain's dopamine systems [reviewed in Taylor et al. (73)]. Human imaging studies have found lowered responsiveness within the mesolimbic as well as the nigrostriatal dopamine system in response to salient stimuli in chronic pain patients (120-123). Chronic pain patients have lower D2 receptor binding $(121,123-125)$ and presynaptic dopamine activity $(126,127)$ in the striatum at rest and following an acute pain stimulus. In animal studies, chronic pain results in decreased neuronal activity, as assessed by c-Fos staining, in the VTA (128), and decreased overall dopamine levels and striatal D2 receptors (129-132). Given the importance of dopamine for motivated behavior (133), it is not surprising that chronic pain animals have been observed to show reduced effort to obtain a food reward, which was linked to depressed activity in the indirect pathway of the ventral striatum (134). Other functions associated with dopamine have similarly been found to be impaired in chronic pain animals, for example, exploratory behavior (135) and selfadministration of rewarding opioids (136); although this has not yet been directly linked to dopamine dysfunction. Considering the importance of the dopaminergic system for goal-directed behavior and reward processes in general, impairments in this system are likely to impact successful coping. Although the

\section{REFERENCES}

1. IASP Taxonomy Working Group. IASP Taxonomy (2011). Available from: https://www.iasp-pain.org/Taxonomy

2. Van Damme S, Crombez G, Eccleston C. Coping with pain: a motivational perspective. Pain (2008) 139:1-4. doi:10.1016/j.pain.2008. 07.022

3. Bandler R, Price JL, Keay KA. Brain mediation of active and passive emotional coping. Prog Brain Res (2000) 122:333-49. doi:10.1016/ S0079-6123(08)62149-4

4. Keay KA, Bandler R. Parallel circuits mediating distinct emotional coping reactions to different types of stress. Neurosci Biobehav Rev (2001) 25:669-78. doi:10.1016/S0149-7634(01)00049-5

5. Maier SF, Seligman ME. Learned helplessness at fifty: insights from neuroscience. Psychol Rev (2016) 123:349-67. doi:10.1037/rev0000033 circuitries for passive pain coping are strongly engaged in patients while experiencing uncontrollable pain, the associated triggering of the reward system via vlPAG and ventral striatum does not lead to the beneficial effects described for healthy individuals (i.e., improving hedonic tone, reducing pain, and promoting health), likely because of the various changes in the brain's dopamine systems associated with chronic pain (73).

To summarize, active strategies in addition to pain acceptance are key for successful coping with chronic pain. But as discussed in this section, there are several neurobiological, in addition to psychological, obstacles to active coping, making the implementation of the most beneficial behaviors more difficult. Neurobiological obstacles include the importance of C-fiber input in chronic pain because it is wired to elicit passivity without leading to the associated benefits of increased vigilance toward rewarding stimuli due to alterations of the brain's dopamine system in chronic pain patients. Supraspinal circuits important for action selection, goal pursuit, and (perceived) control are likely impaired in chronic pain patients, contributing to a viscous circle of pain and unsuccessful coping. And finally, an inactivity response might be inappropriately activated in some chronic pain patients, reflected in complex symptom constellations consisting of widespread pain, hypersensitivity, fatigue, and depressed mood. For successful coping, these difficulties have to be overcome. An understanding of the neurobiological obstacles might be helpful for the healthcare provider to understand and accept when patients display passivity. In addition, patients might benefit from learning about the neurobiological basis of coping and their difficulties to adopt active strategies, similar to the effectiveness of pain neuroscience education in reducing pain, improving function, and lowering disability (137).

\section{AUTHOR CONTRIBUTIONS}

All authors listed have made substantial, direct, and intellectual contribution to the work and approved it for publication.

\section{FUNDING}

WG was supported by a doctoral fellowship provided by the Louise and Alan Edwards Foundation (LAEF). PS was supported by a Canada Research Chair Tier II.

6. Sturgeon JA, Zautra AJ. Psychological resilience, pain catastrophizing, and positive emotions: perspectives on comprehensive modeling of individual pain adaptation. Curr Pain Headache Rep (2013) 17:317. doi:10.1007/ s11916-012-0317-4

7. Morrison I, Perini I, Dunham J. Facets and mechanisms of adaptive pain behavior: predictive regulation and action. Front Hum Neurosci (2013) 7:755. doi:10.3389/fnhum.2013.00755

8. Cooke DF, Graziano MS. Defensive movements evoked by air puff in monkeys. J Neurophysiol (2003) 90:3317-29. doi:10.1152/jn.00513.2003

9. Solomon RL, Kamin LJ, Wynne LC. Traumatic avoidance learning: the outcomes of several extinction procedures with dogs. J Abnorm Psychol (1953) 48:291-302. doi:10.1037/h0058943

10. Perini I, Bergstrand S, Morrison I. Where pain meets action in the human brain. JNeurosci (2013) 33:15930-9. doi:10.1523/JNEUROSCI.313512.2013 
11. Fields HL. A motivation-decision model of pain: the role of opioids. In: Flor H, Kalso E, Dostrovsky JO, editors. Proceedings of the 11th World Congress on Pain. Seattle: IASP Press (2006). p. 449-59.

12. Fields HL. Understanding how opioids contribute to reward and analgesia. Reg Anesth Pain Med (2007) 32:242-6. doi:10.1097/00115550-20070500000012

13. Overmier JB, Seligman ME. Effects of inescapable shock upon subsequent escape and avoidance responding. J Comp Physiol Psychol (1967) 63:28-33. doi:10.1037/h0024166

14. Seligman ME, Maier SF, Geer JH. Alleviation of learned helplessness in the dog. J Abnorm Psychol (1968) 73:256-62. doi:10.1037/h0025831

15. Thornton JW, Jacobs PD. Learned helplessness in human subjects. J Exp Psychol (1971) 87:367-72. doi:10.1037/h0030529

16. Seligman ME, Beagley G. Learned helplessness in the rat. J Comp Physiol Psychol (1975) 88:534-41. doi:10.1037/h0076431

17. Okamoto H, Agetsuma M, Aizawa H. Genetic dissection of the zebrafish habenula, a possible switching board for selection of behavioral strategy to cope with fear and anxiety. Dev Neurobiol (2012) 72:386-94. doi:10.1002/dneu.20913

18. Landgraf D, Long J, Der-Avakian A, Streets M, Welsh DK. Dissociation of learned helplessness and fear conditioning in mice: a mouse model of depression. PLoS One (2015) 10:e0125892. doi:10.1371/journal.pone.0125892

19. Maier SF, Watkins LR. Stressor controllability and learned helplessness: the roles of the dorsal raphe nucleus, serotonin, and corticotropin-releasing factor. Neurosci Biobehav Rev (2005) 29:829-41. doi:10.1016/j.neubiorev.2005.03.021

20. Hiroto DS, Seligman ME. Generality of learned helplessness in man. J Pers Soc Psychol (1975) 31:311-27. doi:10.1037/h0076270

21. Alloy LB, Peterson C, Abramson LY, Seligman ME. Attributional style and the generality of learned helplessness. J Pers Soc Psychol (1984) 46:681-7. doi:10.1037/0022-3514.46.3.681

22. Abramson LY, Seligman MEP, Teasdale JD. Learned helplessness in humans - critique and reformulation. J Abnorm Psychol (1978) 87:49-74. doi:10.1037/0021-843X.87.1.49

23. Raps CS, Peterson C, Reinhard KE, Abramson LY, Seligman ME. Attributional style among depressed patients. JAbnorm Psychol (1982) 91:102-8. doi:10.1037/0021-843X.91.2.102

24. Stonnington CM, Kothari DJ, Davis MC. Understanding and promoting resiliency in patients with chronic headache. Curr Neurol Neurosci Rep (2016) 16:6. doi:10.1007/s11910-015-0609-2

25. Silberstein SD. Meeting acute migraine treatment needs through novel treatment formulations. Neurotherapeutics (2010) 7:153-8. doi:10.1016/j. nurt.2010.03.004

26. Siniatchkin M, Riabus M, Hasenbring M. Coping styles of headache sufferers. Cephalalgia (1999) 19:165-73. doi:10.1046/j.1468-2982.1999.1903165.x

27. Keefe FJ, Rumble ME, Scipio CD, Giordano LA, Perri LM. Psychological aspects of persistent pain: current state of the science. J Pain (2004) 5:195-211. doi:10.1016/j.jpain.2004.02.576

28. Matatko N, Ruppert M, Zierz S, Wieser T, Hasenbring M. Fear-avoidanceand endurance-related responses to pain in migraine patients. 6th Congress of the European Federation of IASP Chapters (EFIC). Lisbon, Portugal (2009).

29. Camacho EM, Verstappen SM, Chipping J, Symmons DP. Learned helplessness predicts functional disability, pain and fatigue in patients with recent-onset inflammatory polyarthritis. Rheumatology (2013) 52:1233-8. doi:10.1093/rheumatology/kes434

30. Bandler R, Keay KA, Floyd N, Price J. Central circuits mediating patterned autonomic activity during active vs. passive emotional coping. Brain Res Bull (2000) 53:95-104. doi:10.1016/S0361-9230(00)00313-0

31. Lumb BM. Inescapable and escapable pain is represented in distinct hypothalamic-midbrain circuits: specific roles for Adelta- and C-nociceptors. Exp Physiol (2002) 87:281-6. doi:10.1113/eph8702356

32. Gandhi W, Becker S, Schweinhardt P. Pain increases motivational drive to obtain reward, but does not affect associated hedonic responses: a behavioural study in healthy volunteers. Eur J Pain (2013) 17(7):1093-103. doi:10.1002/j.1532-2149.2012.00281.x

33. Low LA, Fitzgerald M. Acute pain and a motivational pathway in adult rats: influence of early life pain experience. PLoS One (2012) 7:e34316. doi:10.1371/journal.pone.0034316

34. Eccleston C, Crombez G. Pain demands attention: a cognitive-affective model of the interruptive function of pain. Psychol Bull (1999) 125:356-66. doi:10.1037/0033-2909.125.3.356
35. Buhle J, Wager TD. Performance-dependent inhibition of pain by an executive working memory task. Pain (2010) 149:19-26. doi:10.1016/j. pain.2009.10.027

36. Keogh E, Cavill R, Moore DJ, Eccleston C. The effects of menstrual-related pain on attentional interference. Pain (2014) 155:821-7. doi:10.1016/j. pain.2014.01.021

37. Van Damme S, Legrain V, Vogt J, Crombez G. Keeping pain in mind: a motivational account of attention to pain. Neurosci Biobehav Rev (2010) 34:204-13. doi:10.1016/j.neubiorev.2009.01.005

38. Eccleston C. Chronic pain and attention: a cognitive approach. Br JClin Psychol (1994) 33:535-47. doi:10.1111/j.2044-8260.1994.tb01150.x

39. Van Damme S, Crombez G, Van Nieuwenborgh-De Wever K, Goubert L. Is distraction less effective when pain is threatening? An experimental investigation with the cold pressor task. Eur J Pain (2008) 12:60-7. doi:10.1016/j. ejpain.2007.03.001

40. Van Ryckeghem DM, Crombez G, Eccleston C, Liefooghe B, Van Damme S. The interruptive effect of pain in a multitask environment: an experimental investigation. J Pain (2012) 13:131-8. doi:10.1016/j.jpain.2011.09.003

41. Apkarian AV, Sosa Y, Krauss B, Thomas PS, Fredrickson BE, Levy RE, et al. Chronic pain patients are impaired on an emotional decision-making task. Pain (2004) 108:129-36. doi:10.1016/j.pain.2003.12.015

42. Verdejo-Garcia A, Lopez-Torrecillas F, Calandre EP, Delgado-Rodriguez A, Bechara A. Executive function and decision-making in women with fibromyalgia. Arch Clin Neuropsychol (2009) 24:113-22. doi:10.1093/arclin/acp014

43. Tamburin S, Maier A, Schiff S, Lauriola MF, Di Rosa E, Zanette G, et al. Cognition and emotional decision-making in chronic low back pain: an ERPs study during Iowa gambling task. Front Psychol (2014) 5:1350. doi:10.3389/ fpsyg.2014.01350

44. Koppel L, Andersson D, Morrison I, Posadzy K, Västfäll D, Tinghög G. The effect of acute pain on risky and intertemporal choice. Exp Econ (2017) 1-16. doi:10.1007/s10683-017-9515-6

45. Pais-Vieira M, Mendes-Pinto MM, Lima D, Galhardo V. Cognitive impairment of prefrontal-dependent decision-making in rats after the onset of chronic pain. Neuroscience (2009) 161:671-9. doi:10.1016/j. neuroscience.2009.04.011

46. Becker S, Gandhi W, Elfassy NM, Schweinhardt P. The role of dopamine in the perceptual modulation of nociceptive stimuli by monetary wins or losses. Eur J Neurosci (2013) 38:3080-8. doi:10.1111/ejn.12303

47. Becker S, Gandhi W, Kwan S, Ahmed A, Schweinhardt P. Doubling your payoff: winning pain relief engages endogenous pain inhibition. eNeuro (2015) 2. doi:10.1523/ENEURO.0029-15.2015

48. Carrive P. The periaqueductal gray and defensive behavior: functional representation and neuronal organization. Behav Brain Res (1993) 58:27-47. doi:10.1016/0166-4328(93)90088-8

49. Lovick T, Bandler R. The organization of the midbrain periaqueductal grey and the integration of pain behaviors. In: Hunt S, Koltzenburg M, editors. The Neurobiology of Pain. New York: Oxford University Press Inc. (2005). p. 267-88.

50. Lumb BM. Hypothalamic and midbrain circuitry that distinguishes between escapable and inescapable pain. News Physiol Sci (2004) 19:22-5. doi:10.1152/ nips.01467.2003

51. Lloyd D, Morrison I, Roberts N. Role for human posterior parietal cortex in visual processing of aversive objects in peripersonal space. J Neurophysiol (2006) 95:205-14. doi:10.1152/jn.00614.2005

52. Ezra M, Faull OK, Jbabdi S, Pattinson KT. Connectivity-based segmentation of the periaqueductal gray matter in human with brainstem optimized diffusion MRI. Hum Brain Mapp (2015) 36:3459-71. doi:10.1002/hbm. 22855

53. An X, Bandler R, Ongur D, Price JL. Prefrontal cortical projections to longitudinal columns in the midbrain periaqueductal gray in macaque monkeys. JComp Neurol (1998) 401:455-79. doi:10.1002/ (SICI)1096-9861(19981130)401:4<455::AID-CNE3>3.3.CO;2-Y

54. Floyd NS, Price JL, Ferry AT, Keay KA, Bandler R. Orbitomedial prefrontal cortical projections to distinct longitudinal columns of the periaqueductal gray in the rat. JComp Neurol (2000) 422:556-78. doi:10.1002/1096-9861(20000710)422:4<556::AID-CNE6>3.0.CO;2-U

55. Franklin TB, Silva BA, Perova Z, Marrone L. Prefrontal cortical control of a brainstem social behavior circuit. Nat Neurosci (2017) 20:260-70. doi:10.1038/nn.4470 
56. Euston DR, Gruber AJ, McNaughton BL. The role of medial prefrontal cortex in memory and decision making. Neuron (2012) 76:1057-70. doi:10.1016/j. neuron.2012.12.002

57. Amat J, Sparks PD, Matus-Amat P, Griggs J, Watkins LR, Maier SF. The role of the habenular complex in the elevation of dorsal raphe nucleus serotonin and the changes in the behavioral responses produced by uncontrollable stress. Brain Res (2001) 917:118-26. doi:10.1016/S0006-8993(01)02934-1

58. Weiss JM, Simson PE. Neurochemical and electrophysiological events underlying stress-induced depression in an animal model. Adv Exp Med Biol (1988) 245:425-40. doi:10.1007/978-1-4899-5037-6_46

59. McDevitt RA, Szot P, Baratta MV, Bland ST, White SS, Maier SF, et al. Stressinduced activity in the locus coeruleus is not sensitive to stressor controllability. Brain Res (2009) 1285:109-18. doi:10.1016/j.brainres.2009.06.017

60. Beitz AJ, Clements JR, Mullett MA, Ecklund LJ. Differential origin of brainstem serotoninergic projections to the midbrain periaqueductal gray and superior colliculus of the rat. JComp Neurol (1986) 250:498-509. doi:10.1002/cne. 902500408

61. Graeff FG, Guimaraes FS, De Andrade TG, Deakin JF. Role of 5-HT in stress, anxiety, and depression. Pharmacol Biochem Behav (1996) 54:129-41. doi:10.1016/0091-3057(95)02135-3

62. Roy M, Shohamy D, Daw N, Jepma M, Wimmer GE, Wager TD. Representation of aversive prediction errors in the human periaqueductal gray. Nat Neurosci (2014) 17:1607-12. doi:10.1038/nn.3832

63. Keay KA, Clement CI, Depaulis A, Bandler R. Different representations of inescapable noxious stimuli in the periaqueductal gray and upper cervical spinal cord of freely moving rats. Neurosci Lett (2001) 313:17-20. doi:10.1016/ S0304-3940(01)02226-1

64. Stamford JA. Descending control of pain. Br J Anaesth (1995) 75:217-27. doi:10.1093/bja/75.2.217

65. Cameron AA, Khan IA, Westlund KN, Cliffer KD, Willis WD. The efferent projections of the periaqueductal gray in the rat: a Phaseolus vulgaris-leucoagglutinin study. I. Ascending projections. J Comp Neurol (1995) 351:568-84. doi:10.1002/cne.903510407

66. Geisler S, Derst C, Veh RW, Zahm DS. Glutamatergic afferents of the ventral tegmental area in the rat. J Neurosci (2007) 27:5730-43. doi:10.1523/ JNEUROSCI.0012-07.2007

67. Omelchenko N, Sesack SR. Periaqueductal gray afferents synapse onto dopamine and GABA neurons in the rat ventral tegmental area. J Neurosci Res (2010) 88:981-91. doi:10.1002/jnr.22265

68. Kirik D, Rosenblad C, Bjorklund A. Characterization of behavioral and neurodegenerative changes following partial lesions of the nigrostriatal dopamine system induced by intrastriatal 6-hydroxydopamine in the rat. Exp Neurol (1998) 152:259-77. doi:10.1006/exnr.1998.6848

69. Barneoud P, Descombris E, Aubin N, Abrous DN. Evaluation of simple and complex sensorimotor behaviours in rats with a partial lesion of the dopaminergic nigrostriatal system. Eur J Neurosci (2000) 12:322-36. doi:10.1046/j.1460-9568.2000.00896.x

70. Budygin EA, Park J, Bass CE, Grinevich VP, Bonin KD, Wightman RM. Aversive stimulus differentially triggers subsecond dopamine release in reward regions. Neuroscience (2012) 201:331-7. doi:10.1016/j. neuroscience.2011.10.056

71. Scott DJ, Heitzeg MM, Koeppe RA, Stohler CS, Zubieta JK. Variations in the human pain stress experience mediated by ventral and dorsal basal ganglia dopamine activity. J Neurosci (2006) 26:10789-95. doi:10.1523/ JNEUROSCI.2577-06.2006

72. Wood PB. Mesolimbic dopaminergic mechanisms and pain control. Pain (2006) 120:230-4. doi:10.1016/j.pain.2005.12.014

73. Taylor AM, Becker S, Schweinhardt P, Cahill C. Mesolimbic dopamine signaling in acute and chronic pain: implications for motivation, analgesia, and addiction. Pain (2016) 157(6):19. doi:10.1097/j.pain.0000000000000494

74. Pecina S, Cagniard B, Berridge KC, Aldridge JW, Zhuang XX. Hyperdopaminergic mutant mice have higher "wanting" but not "liking" for sweet rewards. J Neurosci (2003) 23:9395-402.

75. Zink CF, Pagnoni G, Martin-Skurski ME, Chappelow JC, Berns GS. Human striatal responses to monetary reward depend on saliency. Neuron (2004) 42:509-17. doi:10.1016/S0896-6273(04)00183-7

76. Cagniard B, Balsam PD, Brunner D, Zhuang X. Mice with chronically elevated dopamine exhibit enhanced motivation, but not learning, for a food reward. Neuropsychopharmacology (2005) 31:1362-70. doi:10.1038/sj.npp.1300966
77. Yin $\mathrm{HH}$, Zhuang $\mathrm{X}$, Balleine BW. Instrumental learning in hyperdopaminergic mice. Neurobiol Learn Mem (2006) 85:283-8. doi:10.1016/j.nlm.2005.12.001

78. Cooper JC, Knutson B. Valence and salience contribute to nucleus accumbens activation. Neuroimage (2008) 39:538-47. doi:10.1016/j. neuroimage.2007.08.009

79. Smith KS, Berridge KC, Aldridge JW. Disentangling pleasure from incentive salience and learning signals in brain reward circuitry. Proc Natl Acad Sci U S A (2011) 108:E255-64. doi:10.1073/pnas.1101920108

80. Koepp MJ, Gunn RN, Lawrence AD, Cunningham VJ, Dagher A, Jones T, et al. Evidence for striatal dopamine release during a video game. Nature (1998) 393:266-8. doi:10.1038/30498

81. Zald DH, Boileau I, El-Dearedy W, Gunn R, McGlone F, Dichter GS, et al. Dopamine transmission in the human striatum during monetary reward tasks. J Neurosci (2004) 24:4105-12. doi:10.1523/JNEUROSCI.4643-03.2004

82. Oleson EB, Gentry RN, Chioma VC, Cheer JF. Subsecond dopamine release in the nucleus accumbens predicts conditioned punishment and its successful avoidance. JNeurosci (2012) 32:14804-8. doi:10.1523/ JNEUROSCI.3087-12.2012

83. Talmi D, Dayan P, Kiebel SJ, Frith CD, Dolan RJ. How humans integrate the prospects of pain and reward during choice. J Neurosci (2009) 29:14617-26. doi:10.1523/JNEUROSCI.2026-09.2009

84. Koechlin E, Summerfield C. An information theoretical approach to prefrontal executive function. Trends Cogn Sci (2007) 11:229-35. doi:10.1016/j. tics.2007.04.005

85. Vogt BA. Pain and emotion interactions in subregions of the cingulate gyrus. Nat Rev Neurosci (2005) 6:533-44. doi:10.1038/nrn1704

86. Kouneiher F, Charron S, Koechlin E. Motivation and cognitive control in the human prefrontal cortex. Nat Neurosci (2009) 12:939-45. doi:10.1038/ nn. 2321

87. Vogt BA, Vogt L. Cytology of human dorsal midcingulate and supplementary motor cortices. JChem Neuroanat (2003) 26:301-9. doi:10.1016/j. jchemneu.2003.09.004

88. Kolling N, Wittmann M, Rushworth MF. Multiple neural mechanisms of decision making and their competition under changing risk pressure. Neuron (2014) 81:1190-202. doi:10.1016/j.neuron.2014.01.033

89. Mouraux A, Diukova A, Lee MC, Wise RG, Iannetti GD. A multisensory investigation of the functional significance of the "pain matrix". Neuroimage (2011) 54:2237-49. doi:10.1016/j.neuroimage.2010.09.084

90. Cauda F, Torta DM, Sacco K, Geda E, D’Agata F, Costa T, et al. Shared "core" areas between the pain and other task-related networks. PLoS One (2012) 7:e41929. doi:10.1371/journal.pone.0041929

91. Cerliani L, Thomas RM, Jbabdi S, Siero JC, Nanetti L, Crippa A, et al. Probabilistic tractography recovers a rostrocaudal trajectory of connectivity variability in the human insular cortex. Hum Brain Mapp (2012) 33:2005-34. doi:10.1002/hbm.21338

92. Craig AD. Interoception: the sense of the physiological condition of the body. Curr Opin Neurobiol (2003) 13:500-5. doi:10.1016/S0959-4388(03)00090-4

93. Wiech K, Lin CS, Brodersen KH, Bingel U, Ploner M, Tracey I. Anterior insula integrates information about salience into perceptual decisions about pain. J Neurosci (2010) 30:16324-31. doi:10.1523/JNEUROSCI.2087-10.2010

94. Coulombe MA, Erpelding N, Kucyi A, Davis KD. Intrinsic functional connectivity of periaqueductal gray subregions in humans. Hum Brain Mapp (2016) 37:1514-30. doi:10.1002/hbm.23117

95. O’Doherty JP, Dayan P, Friston K, Critchley H, Dolan RJ. Temporal difference models and reward-related learning in the human brain. Neuron (2003) 38:329-37. doi:10.1016/S0896-6273(03)00169-7

96. Eldar E, Hauser TU, Dayan P, Dolan RJ. Striatal structure and function predict individual biases in learning to avoid pain. Proc Natl Acad Sci U S A (2016) 113:4812-7. doi:10.1073/pnas.1519829113

97. Treede RD, Rief W, Barke A, Aziz Q, Bennett MI, Benoliel R, et al. A classification of chronic pain for ICD-11. Pain (2015) 156:1003-7. doi:10.1097/j. pain. 0000000000000160

98. Brown GK, Nicassio PM. Development of a questionnaire for the assessment of active and passive coping strategies in chronic pain patients. Pain (1987) 31:53-64. doi:10.1016/0304-3959(87)90006-6

99. Snow-TurekAL,NorrisMP,Tan G.Activeandpassivecopingstrategiesinchronic pain patients. Pain (1996) 64:455-62. doi:10.1016/0304-3959(95)00190-5

100. Garver MJ, Focht BC, Taylor SJ. Integrating lifestyle approaches into osteoarthritis care. J Multidiscip Healthc (2015) 8:409-18. doi:10.2147/JMDH.S71273 
101. Turk DC, Swanson KS, Tunks ER. Psychological approaches in the treatment of chronic pain patients - when pills, scalpels, and needles are not enough. Can J Psychiatry (2008) 53:213-23. doi:10.1177/070674370805300402

102. Endler NS. Handbook of Coping: Theory, Research, Applications. New York: John Wiley \& Sons (1996).

103. Arnstein P, Caudill M, Mandle CL, Norris A, Beasley R. Self efficacy as a mediator of the relationship between pain intensity, disability and depression in chronic pain patients. Pain (1999) 80:483-91. doi:10.1016/ S0304-3959(98)00220-6

104. Arnstein P. The mediation of disability by self efficacy in different samples of chronic pain patients. Disabil Rehabil (2000) 22:794-801. doi:10.1080/09638280050200296

105. Turner JA, Ersek M, Kemp C. Self-efficacy for managing pain is associated with disability, depression, and pain coping among retirement community residents with chronic pain. J Pain (2005) 6:471-9. doi:10.1016/j. jpain.2005.02.011

106. Carpino E, Segal S, Logan D, Lebel A, Simons LE. The interplay of pain-related self-efficacy and fear on functional outcomes among youth with headache. J Pain (2014) 15:527-34. doi:10.1016/j.jpain.2014.01.493

107. Vlaeyen JW. Learning to predict and control harmful events: chronic pain and conditioning. Pain (2015) 156(Suppl 1):S86-93. doi:10.1097/j. pain. 0000000000000107

108. Van Damme S, Kindermans H. A self-regulation perspective on avoidance and persistence behavior in chronic pain: new theories, new challenges? Clin J Pain (2015) 31:115-22. doi:10.1097/AJP.0000000000000096

109. Bushnell MC, Ceko M, Low LA. Cognitive and emotional control of pain and its disruption in chronic pain. Nat Rev Neurosci (2013) 14:502-11. doi:10.1038/nrn3516

110. Smallwood RF, Laird AR, Ramage AE, Parkinson AL, Lewis J, Clauw DJ, et al. Structural brain anomalies and chronic pain: a quantitative meta-analysis of gray matter volume. J Pain (2013) 14:663-75. doi:10.1016/j.jpain.2013. 03.001

111. Apkarian A, Bushnell M, Schweinhardt P. Representation of pain in the brain. In: McMahon S, Koltzenburg M, Tracey I, Turk D, editors. Textbook of Pain. Philadelphia: Elsevier-Churchill-Livingstone (2013). p. 111-28.

112. Woolf CJ, Wall PD. Relative effectiveness of C primary afferent fibers of different origins in evoking a prolonged facilitation of the flexor reflex in the rat. J Neurosci (1986) 6:1433-42.

113. Ringkamp M, Raja SN, Campbell JN, Meyer RA. Peripheral mechanisms of cutaneous nociception. In: McMahon S, Koltzenburg M, Tracey I, Turk DC, editors. Textbook of Pain. Philadelphia: Elsevier-Churchill-Livingstone (2013). p. 1-30.

114. Schaible HG, Grubb BD. Afferent and spinal mechanisms of joint pain. Pain (1993) 55:5-54. doi:10.1016/0304-3959(93)90183-P

115. Watkins LR, Maier SF. Immune regulation of central nervous system functions: from sickness responses to pathological pain. J Intern Med (2005) 257:139-55. doi:10.1111/j.1365-2796.2004.01443.x

116. Gracely RH, Schweinhardt P. Programmed symptoms: disparate effects united by purpose. Curr Rheumatol Rev (2015) 11:116-30. doi:10.2174/1573 397111666150619095125

117. Loggia ML, Chonde DB, Akeju O, Arabasz G, Catana C, Edwards RR, et al. Evidence for brain glial activation in chronic pain patients. Brain (2015) 138(Pt 3):604-15. doi:10.1093/brain/awu377

118. Miller AH, Haroon E, Raison CL, Felger JC. Cytokine targets in the brain: impact on neurotransmitters and neurocircuits. Depress Anxiety (2013) 30:297-306. doi:10.1002/da.22084

119. Kim WG, Mohney RP, Wilson B, Jeohn GH, Liu B, Hong JS. Regional difference in susceptibility to lipopolysaccharide-induced neurotoxicity in the rat brain: role of microglia. J Neurosci (2000) 20:6309-16.

120. Martikainen IK, Hagelberg N, Mansikka H, Hietala J, Nagren K, Scheinin $\mathrm{H}$, et al. Association of striatal dopamine D2/D3 receptor binding potential with pain but not tactile sensitivity or placebo analgesia. Neurosci Lett (2005) 376:149-53. doi:10.1016/j.neulet.2004.11.045

121. Wood PB, Schweinhardt P, Jaeger E, Dagher A, Hakyemez H, Rabiner EA, et al. Fibromyalgia patients show an abnormal dopamine response to pain. Eur J Neurosci (2007) 25:3576-82. doi:10.1111/j.1460-9568.2007.05623.x
122. Loggia ML, Berna C, Kim J, Cahalan CM, Gollub RL, Wasan AD, et al. Disrupted brain circuitry for pain-related reward/punishment in fibromyalgia. Arthritis Rheumatol (2014) 66:203-12. doi:10.1002/art.38191

123. Martikainen IK, Nuechterlein EB, Pecina M, Love TM, Cummiford CM, Green CR, et al. Chronic back pain is associated with alterations in dopamine neurotransmission in the ventral striatum. J Neurosci (2015) 35:9957-65. doi:10.1523/JNEUROSCI.4605-14.2015

124. Hagelberg N, Forssell H, Aalto S, Rinne JO, Scheinin H, Taiminen T, et al. Altered dopamine D2 receptor binding in atypical facial pain. Pain (2003) 106:43-8. doi:10.1016/S0304-3959(03)00275-6

125. Hagelberg N, Forssell H, Rinne JO, Scheinin H, Taiminen T, Aalto S, et al. Striatal dopamine D1 and D2 receptors in burning mouth syndrome. Pain (2003) 101:149-54. doi:10.1016/S0304-3959(02)00323-8

126. Jaaskelainen SK, Rinne JO, Forssell H, Tenovuo O, Kaasinen V, Sonninen P, et al. Role of the dopaminergic system in chronic pain - a fluorodopa-PET study. Pain (2001) 90:257-60. doi:10.1016/S0304-3959(00)00409-7

127. Wood PB, Patterson JC II, Sunderland JJ, Tainter KH, Glabus MF, Lilien DL. Reduced presynaptic dopamine activity in fibromyalgia syndrome demonstrated with positron emission tomography: a pilot study. JPain (2007) 8:51-8. doi:10.1016/j.jpain.2006.05.014

128. Narita M, Ozaki S, Narita M, Ise Y, Yajima Y, Suzuki T. Change in the expression of $\mathrm{c}$-fos in the rat brain following sciatic nerve ligation. Neurosci Lett (2003) 352:231-3. doi:10.1016/j.neulet.2003.08.052

129. Chang PC, Pollema-Mays SL, Centeno MV, Procissi D, Contini M, Baria AT, et al. Role of nucleus accumbens in neuropathic pain: linked multi-scale evidence in the rat transitioning to neuropathic pain. Pain (2014) 155:1128-39. doi:10.1016/j.pain.2014.02.019

130. Taylor AM, Murphy NP, Evans CJ, Cahill CM. Correlation between ventral striatal catecholamine content and nociceptive thresholds in neuropathic mice. J Pain (2014) 15:878-85. doi:10.1016/j.jpain.2014.05.006

131. Wu Y, Na X, Zang Y, Cui Y, Xin W, Pang R, et al. Upregulation of tumor necrosis factor-alpha in nucleus accumbens attenuates morphine-induced rewarding in a neuropathic pain model. Biochem Biophys Res Commun (2014) 449:502-7. doi:10.1016/j.bbrc.2014.05.025

132. Sagheddu C, Aroni S, De Felice M, Lecca S, Luchicchi A, Melis M, et al. Enhanced serotonin and mesolimbic dopamine transmissions in a rat model of neuropathic pain. Neuropharmacology (2015) 97:383-93. doi:10.1016/j. neuropharm.2015.06.003

133. Berridge KC, Kringelbach ML. Pleasure systems in the brain. Neuron (2015) 86:646-64. doi:10.1016/j.neuron.2015.02.018

134. Schwartz N, Temkin P, Jurado S, Lim BK, Heifets BD, Polepalli JS, et al. Chronic pain. Decreased motivation during chronic pain requires longterm depression in the nucleus accumbens. Science (2014) 345:535-42. doi:10.1126/science.1253994

135. Leite-Almeida H, Almeida-Torres L, Mesquita AR, Pertovaara A, Sousa N, Cerqueira JJ, et al. The impact of age on emotional and cognitive behaviours triggered by experimental neuropathy in rats. Pain (2009) 144:57-65. doi:10.1016/j.pain.2009.02.024

136. Martin TJ, Kim SA, Buechler NL, Porreca F, Eisenach JC. Opioid self-administration in the nerve-injured rat: relevance of antiallodynic effects to drug consumption and effects of intrathecal analgesics. Anesthesiology (2007) 106:312-22. doi:10.1097/00000542-200702000-00020

137. Louw A, Zimney K, Puentedura EJ, Diener I. The efficacy of pain neuroscience education on musculoskeletal pain: a systematic review of the literature. Physiother Theory Pract (2016) 32:332-55. doi:10.1080/09593985.2016.1194646

Conflict of Interest Statement: The authors declare that the research was conducted in the absence of any commercial or financial relationships that could be construed as a potential conflict of interest.

Copyright $\odot 2017$ Gandhi, Morrison and Schweinhardt. This is an open-access article distributed under the terms of the Creative Commons Attribution License (CC BY). The use, distribution or reproduction in other forums is permitted, provided the original author(s) or licensor are credited and that the original publication in this journal is cited, in accordance with accepted academic practice. No use, distribution or reproduction is permitted which does not comply with these terms. 